\title{
Capsule Commentary on Lee et al., Patient use of Email, Facebook, and Physicians' Websites to Communicate with Physicians: A National Online Survey of Retail Pharmacy Users
}

\author{
Thomas R. Yackel, MD MPH MS \\ Department of Medical Informatics and Clinical Epidemiology and Department of Medicine, Division of General Internal Medicine and Geriatrics, \\ Oregon Health \& Science University, Portland, OR, USA.
}

J Gen Intern Med 31(1):102

DOI: $10.1007 / \mathrm{s} 11606-015-3421-4$

(c) Society of General Internal Medicine 2015

$\mathrm{T}$ his study by Lee and colleagues ${ }^{1}$ presents survey data on patients' use and interest in Internet communication with their physician. Patients with a chronic health condition or their families who were part of a national retail pharmacy database were queried, and a surprisingly high number reported contacting their physician via email $(37 \%)$ and Facebook (18\%); fewer reporting using an online website or portal to access the health information of themselves or a family member (4-8\%). Patients were most interested, however, in using a physician's website $(57 \%)$ to access their health information and request prescription refills.

Lee's study points out that, as of 2013, patients are increasingly interested in the ease of web-enabled communication with their physician for the purposes of tracking their health information and requesting prescriptions. Stage 2 of CMS's Meaningful Use program requires that patients have the ability to communicate with their provider. As the percentage of physicians meeting these criteria increases, patients will increasingly have this option. As of 2013, $49 \%$ of physicians had the capability to send messages securely to patients from their electronic health record. ${ }^{2}$

Limitations of this study are notable for the population surveyed-retail pharmacy customers who volunteered to participate in research to obtain coupons for future purchases. Future research should evaluate different patient populations to determine if these trends hold.

A question not addressed by this study is whether unencrypted email and social media are appropriate for patient-physician communication. HIPAA does not prohibit use of email between physicians and patients, ${ }^{3}$ however it is generally advised that secure web portals should be used due to the added security they provide. As Lee's study points out, this is the method of communication most preferred by patients, too.

As the US embraces more patient-centered, value-based care, patients will demand ubiquitous and unfettered access to their health information, including physicians' progress notes. Early studies have shown promise in improving patient satisfaction and measures of patient engagement in their care. ${ }^{4}$ Lee's study suggests that savvy physicians will engage with their patients to find easy and secure electronic methods to meet this emerging demand.

Conflict of Interest: The author has no conflict with any of the material in this manuscript.

Corresponding Author: Thomas R. Yackel, MD MPH MS; Department of Medical Informatics and Clinical Epidemiology and Department of Medicine, Division of General Internal Medicine and GeriatricsOregon Health Science University, Portland, OR, USA (e-mail: yackelt@ohsu.edu).

\section{REFERENCES}

1. Lee JL, Choudhry NK, Wu AW, Matlin OS, Brennan TA, Shrank WH. Patient use of email, Facebook, and physicians' websites to communicate with physicians: A national online survey of retail pharmacy users. J Gen Intern Med. doi:10.1007/s11606-015-3374-7.

2. Office of the National Coordinator for Health Information Technology. "Percent of Physicians with Selected Computerized Capabilities Related to Meaningful Use Objectives," Health IT Quick-Stat \#9. http://dashboard. healthit.gov/quickstats/pages/FIG-physicians-with-meaningful-use-functionalities-in-their-EHR.php. January 2014.

3. US Department of Health and Human Services. "Does the HIPAA Privacy Rule permit health care providers to use e-mail to discuss health issues and treatment with their patients?" http://www.hhs.gov/ocr/privacy/hipaa/ faq/health_information_technology/570.html. December 15, 2008.

4. Delbanco T, et al. Inviting patients to read their doctors' notes: a quasiexperimental study and a look ahead. Ann Intern Med. 2012;157(7):461470 . 